\title{
Psoriasis and cancer. An Australian/New Zealand narrative.
}

Rademaker M, Rubel D, Agnew K, Andrews M, Armour K, Baker C, Foley P, Gebauer K, Goh M, Gupta M, Marshman G, Prince HM, Sullivan J

Address for correspondence: Hon. Associate Professor Marius Rademaker, Waikato Clinical School, Auckland University Medical School, Hamilton, New Zealand

Tel: +64 78381035

Email: Rademaker@xtra.co.nz

- Running Head: Psoriasis and cancer.

- Word Count: 3424

- Tables: 0

- Figures: 0

- Key words: psoriasis, cancer, lymphoma, biologic therapies, immune-modulatory therapies Acknowledgments: We are very grateful to AbbVie Pty Ltd (Australia) for an unrestricted educational grant. They had no influence in the subject matter, discussion or preparation of the manuscript.

Authorship:

- Design, literature search, discussion, conclusions, final version of manuscript - all authors

- Manuscript preparation - MR

- Final manuscript - all authors

Conflicts of Interest:

\begin{tabular}{|l|l|}
\hline Rademaker & Clinical investigator: AbbVie, Douglas Pharmaceuticals. \\
\hline Agnew & None \\
\hline Andrews & None \\
\hline Armour & $\begin{array}{l}\text { Speaker and/or Advisory Board: AbbVie, Janssen-Cilag, Novartis, Sun } \\
\text { Pharma.. }\end{array}$ \\
\hline
\end{tabular}

This is the author manuscript accepted for publication and has undergone full peer review but has not been through the copyediting, typesetting, pagination and proofreading process, which may lead to differences between this version and the Version of Record. Please cite this article as doi: $\underline{10.1111 / a j d .12889}$

This article is protected by copyright. All rights reserved 


\begin{tabular}{|l|l|}
\hline Baker & $\begin{array}{l}\text { Clinical Investigator, speaker and/or advisory board: AbbVie, Janssen, } \\
\text { Novartis, Pfizer }\end{array}$ \\
\hline Foley & $\begin{array}{l}\text { Consultant, investigator, speaker and/or advisor for and/or received travel } \\
\text { grants: 3M/iNova/Valeant, Abbott/AbbVie, Amgen, Biogen Idec, BMS, } \\
\text { Boehringer Ingelheim, Celgene, Celtaxsys, Cutanea, Dermira, Eli Lilly, } \\
\text { Galderma, GSK/Stiefel, Janssen, LEO/Peplin, Novartis, Regeneron, Sanofi } \\
\text { Genzyme, Schering-Plough/MSD, Sun Pharma, UCB, and Wyeth/Pfizer }\end{array}$ \\
\hline Gebauer & $\begin{array}{l}\text { Clinical investigator and/or Advisory Board: AbbVie, Celgene, Janseen, Eli } \\
\text { Lilly }\end{array}$ \\
\hline Goh & none \\
\hline Gupta & Clinical Investigator: AbbVie, Novartis \\
\hline Marshman & $\begin{array}{l}\text { Consultant, investigator, speaker and/or advisor for and/or received travel } \\
\text { and/or research grants: Amgen, BMS, Celgene, Eli Lilly, Janssen, Novartis }\end{array}$ \\
\hline Prince & Clinical Investigator and/or Advisory Board: AbbVie, Amgen, Boehringer- \\
& Ingelheim, Celgene, Eli Lilly, Janssen, Novartis, Sun Pharma \\
\hline Rubel & None \\
\hline
\end{tabular}

Name/Degree/Affiliation

\begin{tabular}{|l|l|l|}
\hline Name & $\begin{array}{l}\text { Highest } \\
\text { Degree }\end{array}$ & Affiliation/Address \\
\hline Rademaker & DM FRCP & $\begin{array}{l}\text { Waikato Clinical School, Auckland University Medical } \\
\text { School, Hamilton, New Zealand }\end{array}$ \\
\hline Rubel & FACD & $\begin{array}{l}\text { Woden Dermatology, Phillip, ACT; and Australian National } \\
\text { University, ACT, Australia }\end{array}$ \\
\hline Agnew & FRACP & $\begin{array}{l}\text { Dermatology Department, Greenlane Clinical Centre \& } \\
\text { Starship Children's Hospital, Auckland, New Zealand }\end{array}$ \\
\hline Armour & FACD & 68 Ipswich Rd, Woolloongabba QLD, Australia \\
\hline Baker & FACD & $\begin{array}{l}\text { Skin \& Cancer Foundation Inc., Carlton, VIC, Australia } \\
\text { The University of Melbourne, St Vincent's Hospital, }\end{array}$ \\
\hline
\end{tabular}

This article is protected by copyright. All rights reserved 


\begin{tabular}{|c|c|c|}
\hline & & VIC, Australia \\
\hline Foley & MD FACD & $\begin{array}{l}\text { The University of Melbourne, St Vincent’s Hospital, } \\
\text { Melbourne; and Fitzroy and Probity Medical Research, Skin } \\
\text { \& Cancer Foundation Inc., Carlton, VIC, Australia }\end{array}$ \\
\hline Gebauer & $\mathrm{ACD}$ & $\begin{array}{l}\text { University of Western Australia, Perth; and Probity Medical } \\
\text { Research, Freemantle, WA, Australia }\end{array}$ \\
\hline Goh & FACD & $\begin{array}{l}\text { St Vincent's Hospital, Melbourne; and Skin \& Cancer } \\
\text { Foundation Inc., Carlton, VIC, Australia }\end{array}$ \\
\hline Gupta & ACD & $\begin{array}{l}\text { Department of Dermatology, Liverpool Hospital, Sydney; The } \\
\text { Skin Hospital, Darlinghurst; and University of New South } \\
\text { Wales, Sydney, NSW, Australia }\end{array}$ \\
\hline Marshman & FACD & $\begin{array}{l}\text { Flinders Medical Centre; and Flinders University Medical } \\
\text { School, Adelaide, SA, Australia }\end{array}$ \\
\hline Prince & $\begin{array}{l}\text { MD, } \\
\text { FRACP }\end{array}$ & $\begin{array}{l}\text { Epworth Healthcare and Sir Peter MacCallum Department of } \\
\text { Oncology, University of Melbourne, VIC, Australia }\end{array}$ \\
\hline Sullivan & FACD & Kingsway Dermatology, Miranda NSW, Australia \\
\hline
\end{tabular}


PROF. MARIUS RADEMAKER (Orcid ID : 0000-0003-3393-6748)

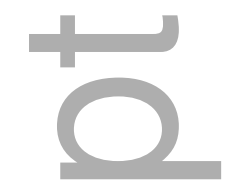

Article type : Review Article

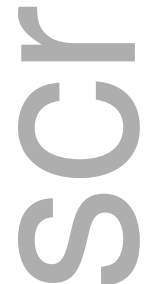

Psoriasis and cancer. An Australian/New Zealand narrative.

\section{$\underline{\text { Abstract }}$}

Patients with psoriasis have an increased risk of cancer, which may be due to impaired immune surveillance, immune-modulatory treatments, chronic inflammation, and/or co-risk factors such as obesity. The increase in treatment-independent solid cancers, including urinary/bladder cancers, oropharynx/larynx, liver/gallbladder, and colon/rectal cancers seem to be linked to alcohol and smoking. Lung cancer and non-melanoma skin cancer are also increased in patients with psoriasis. The risk of non-melanoma skin cancer increases with age and severity of psoriasis. It is also higher in men, particularly for squamous cell carcinoma, which may reflect previous exposure to PUVA and/or ciclosporin. The risk of cutaneous T-cell lymphoma is substantially higher in patients with moderate-to-severe psoriasis.

Biologic therapies are independently associated with a slight increase risk of cancer, but this is less than ciclosporin, with the risk confounded by disease severity, and other co-risk factors. The risk of cancer from low-dose methotrexate, is likely minimal. In contrast, acitretin is likely protective against a variety of solid and haematological malignancies. The data on small molecule therapies such as apremilast is too immature for comment, other that no signal has yet been identified.

The decision whether to stop psoriasis immune-modulatory treatments following a diagnosis of cancer, and when to resume, needs to be considered in the context of the patients' specific cancer. However, there is no absolute need to stop any treatment other than possibly ciclosporin, unless 
there is a concern over an increased risk of serious infection or drug-drug interaction with cancerdirected therapies, including radiotherapy.

\section{Learning points}

- Patients with psoriasis have a slight increase in the relative risk of developing solid organ malignancies, which increases with the severity of psoriasis, but this predominantly reflects the co-risk factors of obesity, smoking and alcohol consumption.

- Patients with psoriasis have a moderate increase in the relative risk of developing haematological malignancies, in particular lymphoma, but the absolute risk remains very low.

- The risk of squamous cell carcinoma is increased in psoriasis, but melanoma risk may be lower

- Reduction in common risk factors such as obesity, smoking and alcohol consumption have a much greater effect on reducing cancer burden in patients with psoriasis, than stopping or avoiding a systemic immune-modulatory agent

\section{$\underline{\text { Introduction }}$}

The general aging of the population, and the consequent relative increase in the prevalence of cancer, has increased the awareness over a potential association between psoriasis and cancer, in particular the contribution of long-term use of biologic and immune-modulatory therapies. The Australasian Psoriasis Collaboration ${ }^{1,2}$ held a round table discussion to address a number of questions in an Australian/New Zealand context:

- Does psoriasis increase the risk of developing cancer?

- Do systemic immune-modulatory treatments increase the risk of developing cancer in patients with psoriasis?

- Do immune-modulatory treatments, in a patient who develops cancer, need to be stopped?

- Should any specific detection/screening programs or cancer prevention strategies, be recommended for patients with psoriasis?

The following narrative makes a number of clinical observations and recommendations based on the published literature and expert clinical opinion. The epidemiological data is variably presented as hazard ratios (HR), adjusted-HR (aHR), relative risks (RR), odds ratio (OR) or standardised incidence ratios (SIR), usually with $95 \%$ confidence intervals $(95 \% \mathrm{CI})$. 


\section{Psoriasis and risk of cancer}

Chronic inflammation is associated with an increased risk of cancer, as demonstrated by the increased tumorigenesis seen in a variety of medical conditions (e.g. gastritis, cystitis, bronchitis, ulcerative colitis, rheumatoid arthritis, etc.). Inflammatory mediators are thought to contribute to neoplasia by inducing pro-neoplastic mutations, adaptive responses, resistance to apoptosis, and environmental changes such as stimulation of angiogenesis. ${ }^{3}$ However, it is difficult to tease out the role of confounding co-morbidities, particularly smoking, alcohol, diabetes and obesity, which have all been shown to independently increase the risk of cancer. ${ }^{4-8}$

\section{$\underline{\text { Solid organ malignancies }}$}

Multiple studies have now shown an increase in the relative risk of some solid organ cancers in patients with psoriasis, particularly those linked to alcohol consumption and cigarette smoking. ${ }^{9-12} \mathrm{~A}$ Taiwanese study found that cancer risk was higher in male than in female patients with psoriasis (aHR: 1.86 vs. 1.14), including cancer of the urinary bladder and skin, followed by oropharynx/larynx, liver/gallbladder, and colon/rectum. ${ }^{13}$ The hazard ratio for cancer varies by age, with younger adult patients at the greatest risk. The risk of cancer in children with psoriasis, on the other hand, was not increased in a retrospective cohort study of biologic-naive children compared with a matched paediatric population. ${ }^{14}$ Interestingly, phototherapy with UVB appeared to reduce the risk of cancer in patients with psoriasis (aHR: 0.52). ${ }^{13}$

A large cohort study of 198,366 patients with psoriasis (186,076 with mild psoriasis, 12,290 moderate-to-severe psoriasis) found the aHR $(95 \% \mathrm{CI})$ for any incident cancer, excluding nonmelanoma skin cancer, was 1.06 (1.02-1.09). For lung cancer, the aHR was 1.12 (1.01-1.25) for patients with mild psoriasis and 1.62 (1.16-2.28) for moderate/severe disease. However, no significant association was seen with cancer of the breast, colon, or prostate in this study. ${ }^{11}$ A smaller study of 32,910 women, 719 with psoriasis, over the age of 65 years, found the aHR (95\% CI) of lung cancer was 1.9 (1.2-3.0), colon cancer 1.6 (1.1-2.5), and any cancer 1.2 (1.0-1.4) in patients with psoriasis, compared to no psoriasis. ${ }^{15}$ When adjusted for smoking, body mass index, education, physical activity, and hormone therapy use, only the association for colon cancer remained with an aHR of $1.6(1.0-2.4)$ and was stronger for patients with severe psoriasis. ${ }^{15}$ 
In a follow-up study of 9,773 Swedish patients who had been admitted to hospital with a diagnosis of psoriasis over the period 1965-1983, 789 of these patients went on to develop a malignancy at least 1 year after their discharge from hospital. The SIR (95\% CI) for all cancers was 1.37 (1.281.47), with an increased SIR of cancers of the penis (4.66), vulva (3.24), the oral cavity and pharynx (2.8), lung (2.13), liver (1.91), pancreas (1.56), kidney (1.56), bladder (1.43) and female breast (1.27). ${ }^{16}$ This data needs to be interpreted with caution as the number of male/female genital cancers was quite low. A large Swedish cohort study of 56,235 breast cancer patients, demonstrated they had an aHR (95\%CI) for developing psoriasis of 1.17 (1.07-1.28), with the risk of being diagnosed with psoriasis being highest shortly after diagnosis, but the risk remained for up to 12 years after their breast cancer. ${ }^{17}$

Data from the Australasian Psoriasis Registry (1,122 patients with 5,195 patient years of follow up), shows a cancer rate (excluding non-melanoma skin cancer) of $0.5 / 100$ patient years, which is similar to the 0.49 and $0.68 / 100$ patient years from the PsoBest and PSOLAR registries respectively (personal communication, Australasian Psoriasis Registry, Apr 2018).

The data on cancer survival in psoriasis patients, compared to individuals without psoriasis, is mixed. In a case-control study of 8,161 psoriasis patients with an aHR (95\% CI) of cancer of 1.53 (1.211.96), there was no difference in cancer survival compared to patients without psoriasis. ${ }^{18}$ However, in a population-based Swedish study of 1,746 psoriasis cancer patients, the HR (95\%CI) for cancer death was 1.26 (1.18-1.35) compared to over a million non-psoriasis cancer patients. Younger cancer patients with psoriasis ( $<65$ years), and those who had been treated for alcohol-related diseases had a worse prognosis. ${ }^{19}$ In a further cohort study using the UK General Practice Research Database, the HR (95\%CI) for dying from a malignancy was 1.41 (1.07-1.86), in 3,603 patients with severe psoriasis, compared to age-matched control without psoriasis. ${ }^{10}$ This equates to an absolute risk of cancer deaths of 39/1,000 patient years, with the excess risk of death from cancer being 1.6 deaths/1,000 patient-years. To put this into perspective, the excess risk of death from cardiovascular disease in patients with psoriasis was calculated as 3.5/1,000 patient-years (absolute risk 61.9/1,000 patient-years). 10

\section{$\underline{\text { Haematological cancers }}$}


Haematological malignancies are also increased in patients with psoriasis. Using the General Practice Research Database ${ }^{20}$ which includes 153,197 patients with psoriasis, the aRR (95\%CI) for lymphoma and its subtypes for mild and severe disease were 1.34 (1.16-1.54) and $1.59(0.88-2.89)$ respectively. In patients with severe psoriasis this was 3.18 (1.0-10.0) for Hodgkin lymphoma, and 10.75 (3.9-29.8) for cutaneous T-cell lymphoma. In a subsequent study using a different United Kingdom database, the aHR (95\% CI) for incident lymphoma in mild psoriasis was 1.31 (1.15-1.49), and 1.89 (1.25-2.86) in severe disease. ${ }^{11}$ Similar results have also been found in other cohort studies, ${ }^{21-23}$ although there may have been some inadvertent misdiagnosis of T-cell lymphoma as psoriasis. Brauchli et al, in a nested case-control study, ${ }^{24}$ documented an OR $(95 \% \mathrm{CI})$ of 2.12 (1.453.10) for lymphohaematopoietic cancers, which was higher in patients who had not received oral anti-psoriasis treatment, or had a disease duration of greater than 2 years (aOR 1.31). ${ }^{24}$ The risk of lymphoma is also elevated in children with psoriasis; a retrospective cohort study in biologic-naive children with psoriasis found an SIR (95\%CI) for lymphoma of 5.42 (1.62-12.94), compared to a matched population of children without psoriasis. ${ }^{14}$

However the absolute risk of haematological cancers attributable to psoriasis is low, with an estimated excess risk of $0.079 / 1,000$ psoriasis patient-years. ${ }^{20}$ The attributable risk for lymphoma has been calculated at $0.17 / 1000$ person-years, meaning one extra lymphoma per 5,823 patients with psoriasis. ${ }^{25}$

\section{$\underline{\text { Skin cancer }}$}

Patients with psoriasis have a higher risk of non-melanoma skin cancer (keratinocytic carcinoma), in particular squamous cell carcinoma (SCC), but this is thought primarily due to previous treatment with photochemotherapy (PUVA) and possibly ciclosporin. ${ }^{26}$ Based on two prospective cohorts, with close to 5 million person-years of follow-up, the RR (95\%CI) of SCC was 1.51 (1.11-2.05). There was no association between psoriasis and the risk of basal cell carcinoma. ${ }^{27} \mathrm{~A}$ cohort study showed the aHR (95\% CI) for non-melanoma skin cancer increased from 1.09 (1.05-1.13) in mild psoriasis to 1.61 (1.42-1.84) for severe psoriasis. ${ }^{11}$ This has been confirmed in a number of other studies. ${ }^{16,22,27-28}$ Despite the increased risk of non-melanoma skin cancer in patients with psoriasis, there is little evidence to show that such skin cancers are either more aggressive, or associated with an increase in mortality. 
Interestingly the risk for melanoma in patients with psoriasis may be lower than in individuals without psoriasis; one Swedish cohort study reported an SIR (95\%CI) of melanoma as 0.32 (0.100.74) compared to non-psoriasis controls. ${ }^{16}$ This is supported by a study comparing 72,739 psoriasis patients with 25,956 non-dermatological controls; the RR (95\%CI) for melanoma was $0.40(0.31$ $0.51){ }^{29}$ There is no immediate explanation for this observation.

\section{Key points:}

- There is a slight increase in the relative risk of developing solid organ malignancies, which increases with the severity of psoriasis, but this predominantly reflects the co-risk factors of obesity, smoking and alcohol consumption.

- Patients with psoriasis have a moderate increase in the relative risk of developing haematological malignancies, in particular lymphoma, but the absolute risk remains very low.

- The risk of squamous cell carcinoma is increased in psoriasis, but melanoma risk may be lower.

\section{Effect of immune-modulatory treatment}

There is on-going speculation as to whether immune-modulatory treatment of psoriasis adds to any cancer burden., ${ }^{9,18,30}$ The difficulty arises with confounding of prescribing immune-modulatory therapies for patients with more severe disease, who consequently have more co-morbidities, which themselves increase the risk of cancer (e.g. obesity, smoking, alcohol, etc.).

The association between PUVA and a substantial increase in the risk of non-melanoma skin cancer, in particular SCC, is well established. A systematic review of 46 PUVA studies has identified that SCC can develop with relatively low UVA exposure, and the risk increases linearly with the number of treatments. ${ }^{31}$ The risk of non-melanoma skin cancer is higher in studies from the United States, compared to European studies; this may partly be explained by the more aggressive PUVA dosage protocols and lighter skin phototypes of the treated patients in the United States. Disturbingly, the increased risk of SCC persists after cessation of PUVA therapy.

An increased risk of basal cell carcinomas has been observed in patients receiving > 100 PUVA treatments. The data for PUVA triggered melanoma is less clear, with most European studies finding no association, but several studies in the United States indicating a 2-fold increase in both invasive and in-situ melanoma after $>200$ PUVA treatments. ${ }^{31}$ 
Reassuringly, patients undergoing treatment with narrow band (nb)UVB, who had not had PUVA, do not appear to have a significant increase in skin cancers. ${ }^{28,32}$ However, there are few published long term follow-up studies of large cohorts who have received $>200$ treatments. Patients who have received both nbUVB and PUVA, have more basal cell carcinomas than the general population. ${ }^{28}$

Whilst ciclosporin-induced skin cancers are well documented in the organ transplant literature, the association is less clear when ciclosporin is used in otherwise healthy individuals with psoriasis. A small nested cohort crossover study of 28 patients on ciclosporin, who were part of a large PUVA follow-up database, ${ }^{33}$ estimated that ciclosporin increased the risk of squamous cell carcinoma 7fold. They equated any use of ciclosporin as the equivalent of 200 PUVA treatments. A European study however found a lower risk; in 1,252 patients with psoriasis treated with ciclosporin, the SIR was 2.1 as compared to the general population, with the risk increasing with longer continuous use (>2 years), exposure to PUVA and/or other immune-modulatory agents. ${ }^{34}$ A subsequent review of 60 studies, which included over 1,700 psoriasis patients treated with ciclosporin, found no skin cancers when ciclosporin had been used for less than 6 months continuously or less than 2 years if used intermittently. 35

With respect to solid organ malignancies, studies on methotrexate and ciclosporin in patients with psoriasis have found no consistent increased risk of non-cutaneous solid tumours. ${ }^{9,18,30,36}$ An Australian study has reported a 50\% excess risk of malignancy among methotrexate-exposed patients with rheumatoid arthritis relative to the general population with an SIR (95\%CI) of 1.5, (1.2-1.9), with a 3-fold increase in melanoma (3.0, 1.2-6.2), a 5-fold increase in non-Hodgkin's lymphoma $(5.1,2.2-10.0)$, and an almost 3 -fold increase in lung cancer $(2.9,1.6-4.8) .{ }^{37}$ The evidence for methotrexate and haematological malignancies is mixed. Earlier studies ${ }^{20,21,38}$ did suggest a slight relative increase in lymphoma in patients treated with methotrexate but, unlike studies in rheumatoid arthritis, subsequent studies have generally not found an association., 9, 18,30,39 Once again, confounding by severity and duration of disease needs to be taken into account.

Hydroxyurea is anecdotally associated with an increased risk of non-melanoma skin cancer when used for a variety of haematological indications (e.g. polycythaemia), ${ }^{40}$ but it is difficult to tease out the effect of the underlying disease from any immune-modulatory effect of hydroxyurea. 
There is no evidence of increased risk of solid cancers with acitretin. Acitretin is beneficial in the management of both non-melanoma skin cancer ${ }^{41-42}$ and cutaneous T-cell lymphoma, ${ }^{43}$ so there are advantages in using acitretin, either as monotherapy, or in combination with biologics, phototherapy or traditional systemic therapies.

There does not appear to be an increased risk of malignancy from fumaric acid esters used to treat psoriasis $^{44}$ although there have been anecdotal reports of treatment emergent melanoma and nonmelanoma skin cancer. ${ }^{45}$

The evidence-base for a potential association between biologic treatments for psoriasis and subsequent development of solid cancers is immature, but so far largely reassuring. ${ }^{9,18,30} \mathrm{~A}$ systematic review of eight prospective cohort studies, mostly of anti-tumour necrosis factor- $\alpha$ $(\mathrm{TNF} \alpha)$, found no evidence for increased risk of cancers (reported as all cancers, lymphoma, melanoma, prostate, colorectal and breast cancer), other than non-melanoma skin cancer. ${ }^{46}$ There are important limitations to this review, as the length of follow-up of the various studies was relatively short, and rigorous inclusion/exclusion criteria were applied. However, the PSOLAR registry did find an increased risk of cancer. ${ }^{38}$ Out of 12,090 patients, 252 malignancies (excluding nonmelanoma skin cancer) were detected. The OR (95\% CI) for any cancer (except non-melanoma skin cancer), for any patients who had received more than 12 months treatment with an anti-TNF- $\alpha$ agent, was $1.54(1.10-2.15){ }^{38}$

There does appear to be an increased risk of non-melanoma skin cancer in patients who have received prolonged treatment with anti-TNF- $\alpha$ agents. The aHR (95\%CI) among individuals ever exposed to a biologic (mostly anti-TNF- $\alpha$ ) was 1.42 (1.12-1.80), but it is difficult to correct for comorbidities, disease severity and duration of treatment. ${ }^{30}$ Patients treated with anti-TNF- $\alpha$ will have had more severe disease with more prolonged or extensive exposure to non-biologic therapies, as compared with patients started more recently on newer biologics. TNF- $\alpha$ plays a vital role in immune-surveillance and has both anti-tumour (apoptosis induction, gene suppression) and protumour (angiogenic, pro-inflammatory immunosuppressant) effects.

The cancer risk of the newer interleukin (IL)-12/23, IL-17, Janus kinase 1/3, and phosphodiesterase4 inhibitors remains to be determined, but no specific flags have yet been raised. ${ }^{9,18,30}$

\section{Key points:}


- PUVA (>200 treatments) and/or >6 months continuous ciclosporin significantly increase the risk of squamous cell carcinoma in patients with psoriasis.

- Immune-modulatory treatment has minimal, if any, significant additional effect on the risk of developing solid cancers in patients with psoriasis.

- Immune-modulatory treatment has minimal, if any, significant additional effect on the risk of developing lymphoma in patients with psoriasis.

- It is possible that early control of moderate/severe psoriasis with appropriate immunemodulatory therapies will significantly reduce the inflammatory burden, which may in turn reduce the relative cancer risk in patients with psoriasis.

\section{Management of psoriasis in a patient with cancer}

Little has been published on the need to stop, or alter, immune-modulatory treatment when a patient with psoriasis is diagnosed with a sporadic cancer. It was the opinion of the expert group that there is no specific requirement to stop psoriasis therapy, with the possible exception of ciclosporin. However, drug-drug (including radiotherapy) interactions must be considered, and any additional increase in infection risk should be taken into account.

There is currently no specific contraindication to starting any of the psoriasis immune-modulatory treatments for patients who have had cancer, who subsequently develop severe psoriasis, with the exception of ciclosporin. As acitretin may reduce the risk of cancer, it may be worthwhile considering co-prescribing acitretin when appropriate.

Key points:

- There is no specific need to stop immune-modulatory treatment of psoriasis after the diagnosis of sporadic cancer, with the possible exception of ciclosporin.

- Be conscious of the potential for drug interactions with any specific cancer therapy.

\section{Screening programmes and chemoprevention.}

There is no data to recommend any specific cancer screening programmes in patients with psoriasis. Although the relative risk for solid organ and haematological cancers is elevated in patients with psoriasis, the absolute risk remains low, particularly in the majority of patients who have mild/moderate disease. Other co-morbidities and risk factors including obesity, smoking and alcohol 
consumption should be considered when assessing need for age-specific cancer screening programmes. The one exception is patients who have received >100 treatments of PUVA, particularly if they have also received ciclosporin; additional regular skin cancer surveillance is strongly recommended.

For a patient with psoriasis and significant sun exposure, but no previous skin cancers, clinicians should encourage year-round sun protection, regular skin checks, weight loss (if BMI>25), topical retinoid, and possibly oral nicotinamide. There is no specific data on chemoprevention of skin cancer in patients with psoriasis, but data can be extrapolated from high-risk organ transplant patients; this would recommend that nicotinamide and low-dose systemic retinoids be considered, ${ }^{47-}$ ${ }^{50}$ particularly for patients who have received $>200$ treatments of PUVA, $>6$ months continuous ciclosporin or $>1$ year of an anti-TNF- $\alpha$. There is also a theoretical role for vaccination against human papilloma yirus, although studies on skin cancer prevention are lacking. In patients with psoriasis and active non-melanoma skin cancer, nicotinamide and standard dose systemic retinoids may be considered.

\section{Conclusion}

Whilst the relative risk of cancer is elevated in psoriasis it would be necessary to treat over 1,500 patients with psoriasis to see an extra non-melanoma skin cancer, and over 5,000 patients with psoriasis for an additional case of lymphoma. ${ }^{25}$ PUVA, ciclosporin and possibly prolonged administration of anti-TNF- $\alpha$ do contribute to a slight increase in non-melanoma skin cancers. The evidence of immune-modulatory treatments contributing to an increased risk of solid organ malignancies is evolving, but seems reassuring.

Reduction in common risk factors such as obesity, smoking and alcohol consumption have a much greater effect on reducing cancer burden in patients with psoriasis, than the stopping or avoidance of a systemic immune-modulatory agent. It is possible that early control of moderate/severe psoriasis with appropriate immune-modulatory therapies may actually reduce the relative cancer risk in patients.

\section{$\underline{\text { References }}$}


1. Rademaker M, Gupta M, Andrews M, et al. The Australasian Psoriasis Collaboration view on Methotrexate for psoriasis in the Australasian setting. Australas J Dermatol. 2017; 58: 166-70.

2. Rademaker M, Agnew K, Andrews M, et al. Psoriasis in those planning a family, pregnant or breast-feeding. The Australasian Psoriasis Collaboration. Australas J Dermatol. 2017 May 25. doi: 10.1111/ajd.12641.

3. Shacter E, Weitzman SA. Chronic inflammation and cancer. Oncology (Williston Park) $2002 ; 16: 217-26$.

4. Connor J. Alcohol consumption as a cause of cancer. Addiction. 2017;112:222-8.

5. Rehm J, Shield K. Alcohol consumption. In: Stewart BW, Wild CB, ed. World Cancer Report 2014. Lyon, France: International Agency for Research on Cancer. 2014; p96-104.

6. Wolin KY, Carson K, Colditz GA. Obesity and cancer. Oncologist 2010;15:556-65.

7. Calle EE, Thun MJ. Obesity and cancer. Oncogene 2004;23:6365-78.

8. Chiu CC, Huang CC, Chen YC, et al. Increased risk of gastrointestinal malignancy in patients with diabetes mellitus and correlations with anti-diabetes drugs: a nationwide population-based study in Taiwan. Intern Med. 2013;52:939-46.

9. Geller S, Xu H, Lebwohl M, Nardone B, Lacouture ME, Kheterpal M. Malignancy Risk and Recurrence with Psoriasis and its Treatments: A Concise Update. Am J Clin Dermatol. 2017 Dec 19. doi: 10.1007/s40257-017-0337-2.

10. Abuabara K, Azfar RS, Shin DB, Neimann AL, Troxel AB, Gelfand JM. Cause-specific mortality in patients with severe psoriasis: a population-based cohort study in the U.K. Br J Dermatol. 2010;163:586-92.

11. Chiesa Fuxench ZC, Shin DB, Ogdie Beatty A, Gelfand JM. The risk of cancer in patients with psoriasis: A Population-Based Cohort Study in the Health Improvement Network. JAMA Dermatol. 2016;152:282-90.

12. Margolis D, Bilker W, Hennessy S, Vittorio C, Santanna J, Strom BL. The risk of malignancy associated with psoriasis. Arch Dermatol. 2001;137:778-83

This article is protected by copyright. All rights reserved 
13. Chen YJ, Wu CY, Chen TJ, Shen JL, Chu SY, Wang CB, Chang YT. The risk of cancer in patients with psoriasis: a population-based cohort study in Taiwan. J Am Acad Dermatol. 2011;65:84-91.

14. Gu Y, Nordstrom BL. The risk of malignancy among biologic-naive pediatric psoriasis patients: a retrospective cohort study in a US claims database. J Am Acad Dermatol. 2017;77:293-301.e1.

15. Prizment AE, Alonso A, Folsom AR, et al. Association between psoriasis and incident cancer: the Iowa's Women's Health Study. Cancer Causes Control. 2011;22:1003-10.

16. Boffetta P, Gridley G, Lindelöf B. Cancer risk in a population-based cohort of patients hospitalized for psoriasis in Sweden. J Invest Dermatol. 2001;117:1531-7.

17. Yang H, Brand JS, Li J, et al. Risk and predictors of psoriasis in patients with breast cancer: a Swedish population- based cohort study. BMC Medicine 2017;15:154.

18. Reddy SP, Martires K, Wu JJ. The risk of melanoma and hematologic cancers in patients with psoriasis. J Am Acad Dermatol. 2017;76:639-47.

19. Shu X, Ji J, Sundquist J, Sundquist K, Hemminki K. Survival in cancer patients hospitalized for psoriasis: a population-based cohort study in Sweden. Br J Dermatol. 2011;165:129-36.

20. Gelfand JM, Shin DB, Neimann AL, Wang X, Margolis DJ, Troxel AB. The risk of lymphoma in patients with psoriasis. J Invest Dermatol. 2006;126:2194-201.

21. Gelfand JM, Berlin J, Van Voorhees A, Margolis DJ. Lymphoma rates are low but increased in patients with psoriasis: results from a population-based cohort study in the United Kingdom. Arch Dermatol. 2003;139:1425-9.

22. Lee MS, Lin RY, Chang YT, Lai MS. The risk of developing non-melanoma skin cancer, lymphoma and melanoma in patients with psoriasis in Taiwan: a 10-year, population-based cohort study. Int J Dermatol. 2012;51:1454-60.

23. Kamstrup MR, Skov L, Zachariae C, Thyssen JP, Egeberg A. Psoriasis and risk of malignant lymphoma: A population-based cohort study. Br J Dermatol. 2017 Dec 16. doi: 10.1111/bjd.16245. 
24. Brauchli YB, Jick SS, Miret M, Meier CR. Psoriasis and risk of incident cancer: an inception cohort study with a nested case-control analysis. J Invest Dermatol. 2009;129:2604-12.

25. Saleem MD, Kesty C, Feldman SR. Relative versus absolute risk of comorbidities in patients with psoriasis. J Am Acad Dermatol. 2017;76:531-7.

26. Pouplard C, Brenaut E, Horreau C, et al. Risk of cancer in psoriasis: a systematic review and meta-analysis of epidemiological studies. J Eur Acad Dermatol Venereol. 2013;27(Suppl 3):36-46.

27. Dai H, Li WQ, Qureshi AA, Han J. Personal history of psoriasis and risk of nonmelanoma skin cancer (NMSC) among women in the United States: A population-based cohort study. J Am Acad Dermatol. 2016;75:731-5.

28. Hearn RM, Kerr AC, Rahim KF, Ferguson J, Dawe RS. Incidence of skin cancers in 3867 patients treated with narrow-band ultraviolet B phototherapy. Br J Dermatol. 2008;159:931-5. 29. Paradisi A, Tabolli S, Didona B, Sobrino L, Russo N, Abeni D. Reduced frequency of melanoma in 72,739 patients with psoriasis: A retrospective study. Eur J Dermatol. 2015;25:133-7.

30. Asgari MM, Ray GT, Geier JL, Quesenberry CP. Malignancy rates in a large cohort of patients with systemically treated psoriasis in a managed care population. J Am Acad Dermatol. 2017;76:632-8.

31. Archier E, Devaux S, Castela E, et al. Carcinogenic risks of psoralen UV-A therapy and narrowband UV-B therapy in chronic plaque psoriasis: a systematic literature review. J Eur Acad Dermatol Venereol. 2012;26 (Suppl 3):22-31.

32. Man I, Crombie IK, Dawe RS, Ibbotson SH, Ferguson J. The photocarcinogenic risk of narrowband UVB (TL-01) phototherapy: early follow-up data. Br J Dermatol. 2005;152:755-7.

33. Marcil I, Stern RS. Squamous-cell cancer of the skin in patients given PUVA and cyclosporin: nested cohort crossover study. Lancet. 2001;358:1042-5.

34. Paul CF, Ho VC, McGeown C, et al. Risk of malignancies in psoriasis patients treated with cyclosporine: a 5 y cohort study. J Invest Dermatol. 2003;120:211-6. 
35. Muellenhoff MW, Koo JY. Cyclosporine and skin cancer: an international dermatologic perspective over 25 years of experience. A comprehensive review and pursuit to define safe use of cyclosporine in dermatology. J Dermatolog Treat. 2012;23:290-304.

36. Väkevä L, Reitamo S, Pukkala E, Sarna S, Ranki A. Long-term follow-up of cancer risk in patients treated with short-term cyclosporine. Acta Derm Venereol. 2008;88:117-20.

37. Buchbinder R, Barber M, Heuzenroeder L, et al. Incidence of melanoma and other malignancies among rheumatoid arthritis patients treated with methotrexate. Arthritis Rheum. 2008;59:794-9.

38. Stern RS. Lymphoma risk in psoriasis: results of the PUVA follow-up study. Arch Dermatol. 2006; $142: 1132-5$.

39. Fiorentino D, Ho V, Lebwohl MG' et al. Risk of malignancy with systemic psoriasis treatment in the Psoriasis Longitudinal Assessment Registry. J Am Acad Dermatol. 2017;77:845-54.e5.

40. Callot-Mellot $\mathrm{C}$, Bodemer $\mathrm{C}$, Chosidow $\mathrm{O}$, et al. Cutaneous carcinoma during long-term hydroxyurea therapy: a report of 5 cases. Arch Dermatol. 1996;132:1395-7.

41. Que SKT, Zwald FO, Schmults CD. Cutaneous squamous cell carcinoma: Management of advanced and high-stage tumors. J Am Acad Dermatol. 2018;78:249-61.

42. McKenna DB, Murphy GM. Skin cancer chemoprophylaxis in renal transplant recipients: 5 years of experience using low-dose acitretin. Br J Dermatol. 2001;140:656-60.

43. Huen AO, Kim EJ. The Role of Systemic Retinoids in the Treatment of Cutaneous T-Cell Lymphoma. Dermatol Clin. 2015;33:715-29.

44. Balak DM. Fumaric acid esters in the management of psoriasis. Psoriasis (Auckl). 2015;5:9-23. 45. Barth D, Simon JC, Wetzig T. Malignant melanoma during treatment with fumaric acid esters coincidence or treatment-related? J Dtsch Dermatol Ges. 2011;9:223-5.

46. Peleva E, Exton LS, Kelley K, Kleyn CE, Mason KJ, Smith CH. Risk of cancer in patients with psoriasis on biological therapies: a systematic review. Br J Dermatol. 2018;178:103-13. 
47. Chen AC, Martin AJ, Choy B, et al. A Phase 3 Randomized Trial of Nicotinamide for SkinCancer Chemoprevention. N Engl J Med. 2015;373:1618-26.

48. George R, Weightman W, Russ GR, Bannister KM, Mathew TH. Acitretin for chemoprevention of non-melanoma skin cancers in renal transplant recipients. Aust J Dermatol. 2002;43:269-73.

49. Harwood CA, Leedham-Green M, Leigh IM, Proby CM. Low-dose retinoids in the prevention of cutaneous squamous cell carcinomas in organ transplant recipients: a 16-year retrospective study. Arch Dermatol. 2005;141:456-64.

50. de Sevaux RG, Smit JV, de Jong EM, van de Kerkhof PC, Hoitsma AJ. Acitretin treatment of premalignant and malignant skin disorders in renal transplant recipients: clinical effects of a randomized trial comparing two doses of acitretin. J Am Acad Dermatol. 2003;49:407-12.

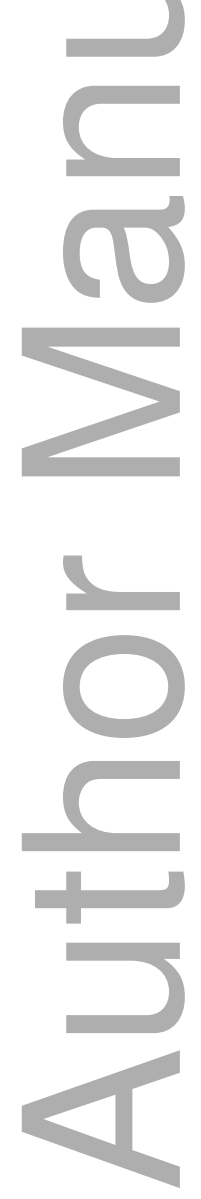

This article is protected by copyright. All rights reserved 


\section{University Library}

\section{- M I N E R VA}

\section{A gateway to Melbourne's research publications}

Minerva Access is the Institutional Repository of The University of Melbourne

\section{Author/s:}

Rademaker, M;Rubel, DM;Agnew, K;Andrews, M;Armour, KS;Baker, C;Foley, P;Gebauer, K;Goh, MSY;Gupta, M;Marshman, G;Prince, HM;Sullivan, J

Title:

Psoriasis and cancer. An Australian/New Zealand narrative

Date:

2019-02-01

\section{Citation:}

Rademaker, M., Rubel, D. M., Agnew, K., Andrews, M., Armour, K. S., Baker, C., Foley, P., Gebauer, K., Goh, M. S. Y., Gupta, M., Marshman, G., Prince, H. M. \& Sullivan, J. (2019). Psoriasis and cancer. An Australian/New Zealand narrative. AUSTRALASIAN JOURNAL OF DERMATOLOGY, 60 (1), pp.12-18. https://doi.org/10.1111/ajd.12889.

Persistent Link:

http://hdl.handle.net/11343/284252 